\title{
SUBBOTTOM PROFILING INVESTIGATION OF SINKHOLE LAKE STRUCTURE IN BAY AND WASHINGTON COUNTIES, FLORIDA
}

\author{
Thomas L. Dobecki, Sam B. Upchurch, Thomas M. Scott, \\ Beth Fratesi, Michael C. Alfieri \\ SDII Global Corporation, 4509 George Rd., Tampa, Florida, 33634 USA, tdobecki@sdii-global.com
}

\begin{abstract}
The sandhill lakes of Bay and Washington Counties, Florida, are deep, pristine environments which owe their existence to sinkhole activity as observed in limited bathymetric maps and in the appearance of small circular depressions around their perimeters ("string of pearls") observed on aerial photography especially during low water level periods. However, little investigative information exists that shows the internal, deep structure of these lakes and how that structure might affect interaction with groundwater flow and lake levels.
\end{abstract}

High resolution seismic reflection surveying with a marine subbottom profiler (SBP) was applied over reconnaissance profile lines on a series of these sandhill lakes in order to investigate the deep structures of the lakes for purposes of determining the mode of sinkhole development within each lake and their relationships with subjacent aquifers, specifically the Floridan aquifer system (FAS). The SBP provided mapping of the bathymetry (maximum $15-32 \mathrm{~m}$ water depth) and subbottom structure up to an additional $18-24 \mathrm{~m}$ below the bottom, all with a theoretical resolution of approximately $0.10 \mathrm{~m}$ bed thickness.

The resulting SBP profiles showed that a) the lakes form through the coalescence of numerous small sinkhole features, b) the sinkhole features penetrate the uppermost FAS, disrupting the overlying sediments, and c) multiple stages of sinkhole development and sediment movement are exhibited in the subbottom strata.

\section{Introduction}

The sandhill lakes region (Figure 1) of the Florida Panhandle occupies portions of Washington and Bay Counties (north of Panama City), Florida. It is a region of some 200 crystal-clear lakes that owe their existence to sinkhole activity. The lakes are often circular in plan with a striking blue color owing to low nutrient levels and pure white sugarsand bottoms, and their internally drained basins are the homes of many endangered or threatened floral and faunal species, including bald eagles, gopher tortoises, smoothbark St. John's wort, and several species of carnivorous sundews.

It has long been common knowledge that the lakes have sinkhole origins (Grubbs, et al., 1995; Pratt, et al., 1996), but after viewing shorelines during periods of drought when lake levels drop, it was suspected that the mode of creation and growth was complex as demonstrated by the "string of pearls" appearance of new, smaller depressions forming around the perimeter of the lakes (Figure 2). In addition, there were questions regarding the interaction and connection between the lakes, the underlying surficial (unconfined) aquifer, and the deep, semi-confined Florida aquifer system (FAS). As a means of developing an understanding of lake structure and growth mechanisms as well as an understanding of the interconnection between the lakes and the FAS, a program of marine (lake) geophysical imaging was conducted in five sandhill lakes in the region. The method applied is high resolution seismic reflection profiling or sub-bottom profiling.

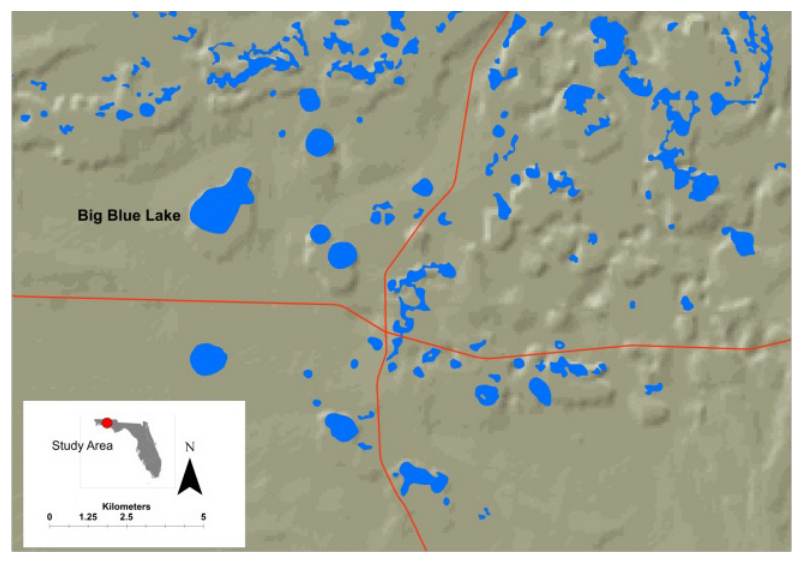

Figure 1. Plan view of sandhill lakes of NW Florida. 


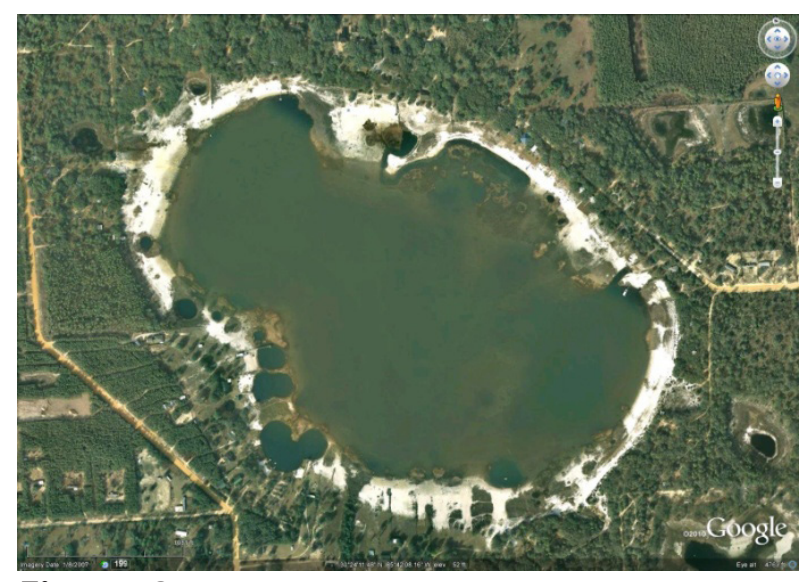

Figure 2. Aerial photograph of a sandhill lake showing a "string of pearls" of new, recent sinkholes along the lake shore.

\section{SBP Geophysical Methodology}

The acoustic sub-bottom profiler (SBP) is a geophysical technology that measures the depth of water as well as thickness and structure of sub-bottom sediments using acoustic echo sounding principles. The technology is quite similar to simple depth gauges/fish finders found on boats. The principal difference is that the SBP employs an acoustic source that has increased signal power and somewhat lower frequency than a common depth finder. This allows for some penetration into the bottom sediments. Reflections of the acoustic signals from the sediment layers may also be detected as the boat cruises along a lake-crossing profile (Tihansky, et al., 1996; Reich, et al., 2012).

SDII employed the Syqwest StrataBox SBP system consisting of a processor/controller circuitbox, an acoustic piezoelectric source $(10,000 \mathrm{~Hz}$ center frequency), and an auxiliary satellite GPS system - all controlled by a laptop computer. The system is battery powered, and instrument specifications quote water penetration depths up to 150 meters (490 feet) and up to 40 meters (130 feet) of sub-bottom penetration under ideal conditions. With an assumed seismic compression wave velocity of $1,500 \mathrm{~m} / \mathrm{sec}$ for the water and saturated sediments, the $10,000 \mathrm{~Hz}$ source can realize resolution of beds on the order of one wavelength or less (approximately 0.10 meter). Figure 3 shows the boat used with the transducer in the water just below the GPS antenna.

Operationally, the acoustic source is lowered below the water surface to ensure excellent coupling of the acoustic waves into the water column. The source is directed downwards to scan below the boat. Communications are established between the computer and the GPS system so that positional coordinates can be recorded concurrently with the acoustic echoes. Parameters (e.g. maximum depth range, instrument gains) are optimized for a given lake, and a digital file is opened. The boat is piloted on a straight-line course across the lake, and the depth-converted cross-section is displayed in real time during the crossing. Figure 4 is a representative SBP cross-section acquired on one of the lakes in the study area. The only post-acquisition processing (besides printing) of these data sets was a mute to remove reflections from within the water column caused by vegetative masses and fish.

The following principal features can be seen in the example cross section in Figure 4 and in other cross sections included here.

- Time zero (the water surface, 0 meters depth) is represented by the horizontal line across the top of the section.

- The total horizontal length of the section is labeled at the top of the section. Actual position coordinates of any point along the cross-section can be determined by playing back the SBP file through the acquisition program and using a cursor to determine GPS coordinates at any specific point of interest.

- The vertical scale is depth in meters. For the sandhill lakes project, we used a maximum depth range of 0-36.5 meters (0-120 feet).

- The primary reflection from the bottom of the lake is the bright reflection interface indicated as "primary (bottom) reflection" on Figure 4. This

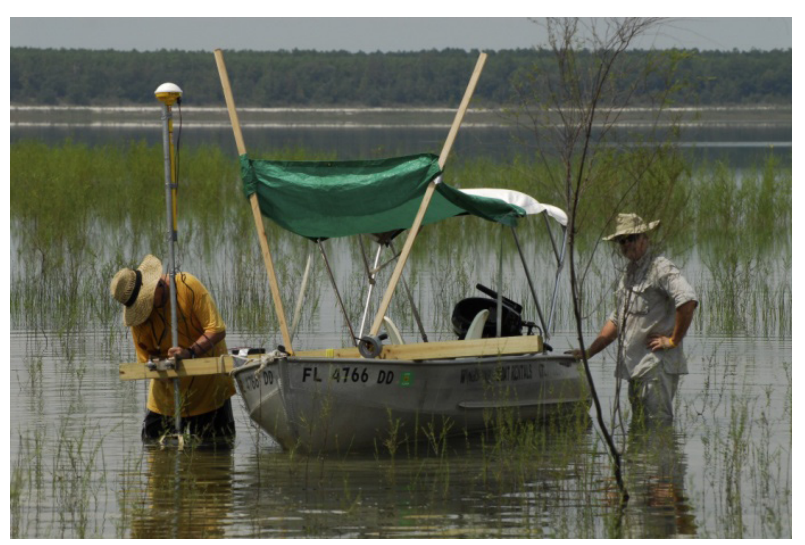

Figure 3. Photograph of SYQWEST SBP system mounted on an aluminum boat. 


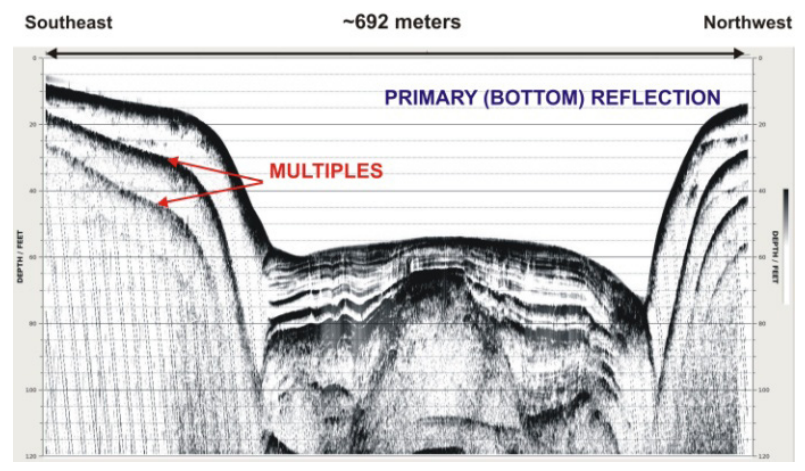

Figure 4. Example SBP section.

represents an acoustic wave that traveled down to the lake bottom and reflected back up to the boat (down plus up path).

- The secondary reflections labeled as "multiples" are primary reflections that have reflected back downwards from the water surface and represent second, third, fourth, etc. roundtrips of the signal. Multiple reflections become a noise issue when water depth is shallow, but as depth increases the multiples begin to disappear off the bottom of the profile because the round trip time is double, triple, etc. that of a primary reflection.

- Between the primary bottom reflection and the first multiple, we see clear reflections from subbottom sediment layers.

\section{SBP Results ("Big Blue Lake")}

Big Blue Lake was the largest of the five lakes profiled. The lake is approximately 230 hectares in size $(2,300$ $\mathrm{m}$ by $1,000 \mathrm{~m}$ ). A total of nine profiles were acquired as shown on Figure 5. In this manuscript, we present the results of two specific profiles, BB-3 and BB-4.

Profile BB-3 is approximately 2,027 meters long running down the long axis of Big Blue Lake from north to south (Figure 5). Profile BB-4 is a shorter (945-meter) profile extending from southeast to northwest along the southern shore of Big Blue Lake. This profile extended over some smaller circular depressions observed on historical air photographs taken when lake levels were lower.

Data were acquired over a two-day period due to heavy afternoon thundershowers typical of this region in the summer months. All geophysical activities are curtailed at the first sign of lightning.

\section{Profile BB-3 - Big Blue Lake}

Figure 6 presents the SBP image acquired along Profile BB-3. There is significant vertical exaggeration on this profile as it represents a very long profile. The main feature displayed on this profile is the lake bottom bathymetry varying between 4.5 and 22.9 meters water depth. This vertical exaggeration emphasizes the features that indicate that Big Blue Lake has not formed as the result of a central, conical depression related to a single sinkhole throat. From the image, we see that along this profile there are at least six discrete sinkhole structures, and some of these are well developed (i.e., they are deep with steep sides) while others appear to be just starting to depress the lake bottom. The deepest depression on this profile shows evidence of slumping.

Note in Figure 6 that the depressions have a common depth, which is at or below the depth of the semiconfining strata that separate the surficial aquifer and the FAS. The small sediment volumes highlighted in yellow on Figure 6 represent accumulations that have developed in the bottoms of the depressions after sinkhole development. Since the lakes have no surface water tributaries, these sediment accumulations were derived from slope wash into the lake from the portion of the closed depression that contains the lake and/or slumps from the sides of the depressions.

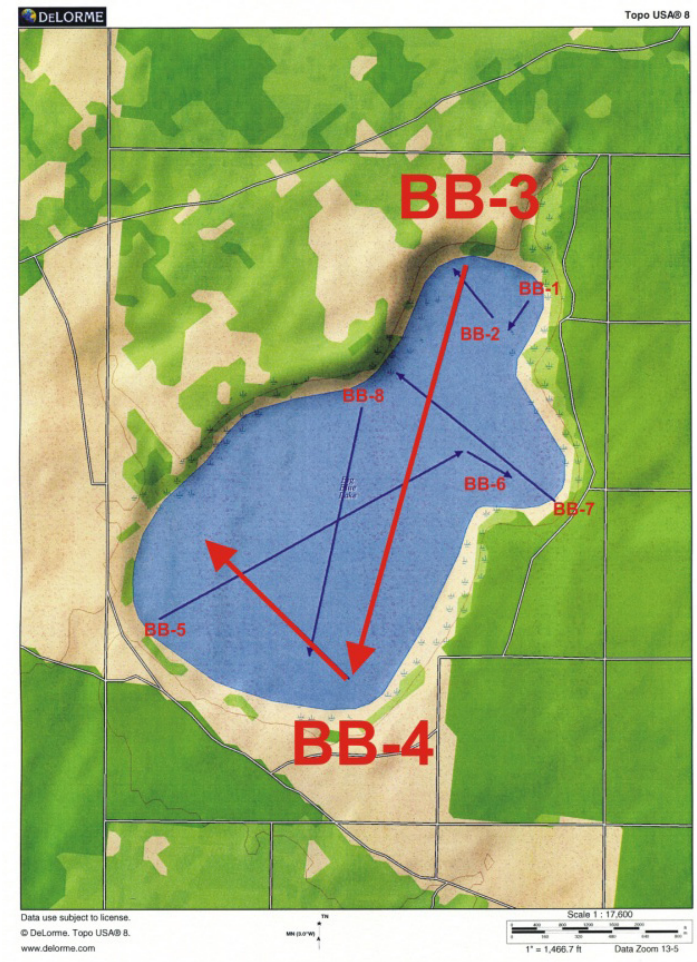

Figure 5. Map of Big Blue Lake showing SBP profiles. The results of Profiles BB-3 and BB-4 are presented in this manuscript. 


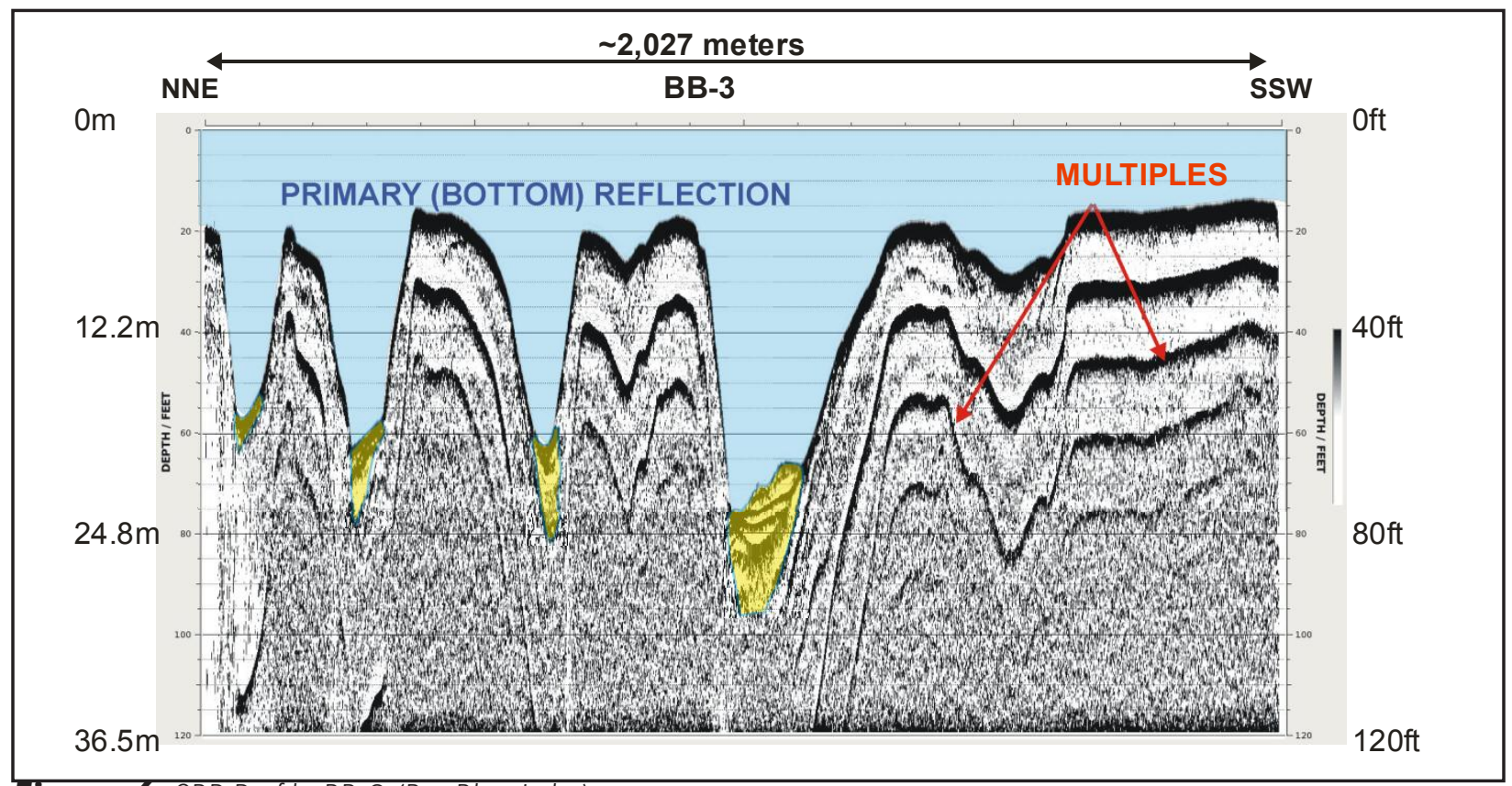

Figure 6. SBP Profile BB-3 (Big Blue Lake).

\section{Profile BB-4 - Big Blue Lake}

Profile BB-4 (Figure 7) is a much less compressed image that shows not only the structure of the lake bottom bathymetry (as per Figure 6), but it also shows considerable $(22 \mathrm{~m})$ penetration into the lake bottom sediments.
Figures 6 and 7 demonstrate that, even though the lake appears to be a single, large sinkhole depression in plan view, it actually consists of a series of overlapped and coalesced individual sinkhole structures. These overlapped sinkhole structures, which are highlighted in yellow in Figure 7, appear distorted because of a complex

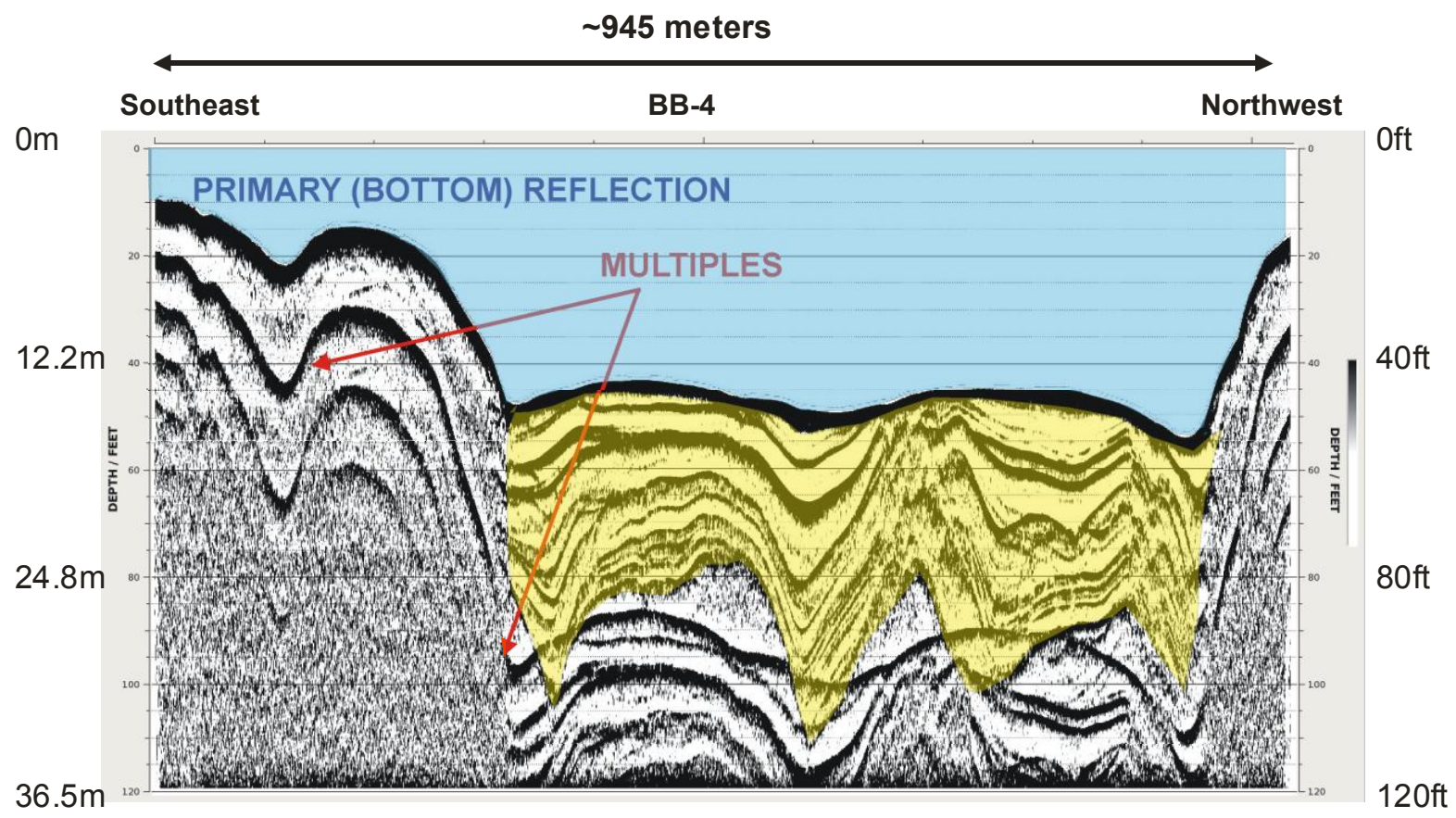

Figure 7. SBP Profile BB-4 (Big Blue Lake). 
history of multiple subsidence events and development of slump structures.

Figure 7 reveals a smaller (newer?) sinkhole structure forming to the left of the main depression. There are also slump features on the flanks of the main sinkhole depression suggesting that the larger, basinal features and internal sinkholes are continuing to grow.

The maximum observed depth of subbottom penetration is approximately 33 meters. The water surface elevation at the time the SBP profile was acquired was approximately 18 meters MSL. The maximum depth of penetration therefore, would extend down to approximately elevation -15 meters, MSL. Local test borings drilled some 150 meters from the water put the elevation of the top of the FAS at approximately -13 meters, MSL. The disrupted sediment patterns observed on the SBP profile then intersect the FAS, verifying direct connection between the lake and the underlying FAS.

The small, relatively new sinkhole on the left hand side of profile BB-4 is an example of several small, steep sided depressions along the perimeter of the lake. Given that the sinkholes appear to "bottom out" at the top of the limestone of the Floridan aquifer, it appears that there is a limit as to the available sediment to ravel into the Floridan from the center of the lake. Rather, the lake appears to be growing laterally by development of new, lake-margin sinks.

Many of the sandhill lakes in the area show these young, lake-margin sinks in such abundance as to resemble a "string of pearls" (Figure 2).

\section{Conclusions}

- SBP is an excellent tool for determination of the origin and geometry of sandhill lakes, which typically have little clay or organic sediment. Penetration is excellent, and sinkhole structures and slump features are readily apparent.

- The sandhill lakes of Washington and Bay counties, Florida, have formed by coalescence of a complex of smaller sinkholes that have a common apparent depth at the approximate top of the underlying limestone of the FAS. The FAS in the area is characterized by many springs and well-developed conduit flow, so the sandhill lakes appear to represent the "headwaters" of the conduit systems.
- The lakes appear to be growing in surface area by development of small, peripheral, lake-margin sinkholes rather than by suffusion or slump of perimeter sand into the existing depression in the lake bottoms.

\section{References}

Grubbs, JW. 1995. Evaluation of ground-water flow and hydrologic budget for Lake Five-O, a seepage lake in northwestern Florida. US Geological Survey Water-Resources Investigations Report 94-4145.

Pratt, TR, Richards, CJ, Milla, KA, Wagner, JR, Johnson, JL, and Curry, RJ. 1996. Hydrogeology of the Northwest Florida Water Management District. Northwest Florida Water Management District Water Resources Special Report 96-4.

Tihansky, AB, Arthur, JD, and DeWitt, DW. 1996. Sublake geologic structure from high-resolution seismic-reflection data from four sinkhole lakes in the Lake Wales Ridge, Central Florida, US Geological Survey Open-file Report 96-224.

Reich, C, Flocks, J, and Davis, J. 2012. Geophysical investigation of Sentinel Lakes in Lake, Seminole, Orange, and Volusia Counties, Florida, US Geological Survey Open-file Report 2012-1201. 
212 NCKRI SYMPOSIUM 2 I3TH SINKHOLE CONFERENCE 